\title{
The Existing Problems and the Possible Reformation of UK University Admission System
}

\author{
Lidi Fang
}

University College London, London, England, WC1E 6BT,

Corresponding author. Email: freddie.fang.20@ucl.ac.uk

\begin{abstract}
This paper shows the current situation and state of UK's university admission about how it is run generally and points out a few problems related to such matching mechanism between students and universities such as the shortcomings in stability, strategy-proof and Pareto-efficiency. In 2015, the UK government introduced the new A-level rules to decouple the AS and A-level exam which means the AS exam will not longer count towards A-level final results. By comparing the Deferred Acceptance algorithm matching with the current one used by the UK university matching system, we can see that result shows that DA mechanism gives a better matching outcome related to stability and strategy-proof. The shortcomings under the DA matching are also shown in the following such as lacking of Pareto-efficiency. At last, the paper illustrates some possible policies that can be implemented under DA matching and how these policies give a better matching between students and universities in the UK. The paper uses comparing method and gives a possible alternative method to make the matching between students and universities in the UK more stabler and equal.
\end{abstract}

Keywords: Deferred Acceptance, Stability, Strategy-proof, Pareto-efficiency, UK university admission system

\section{INTRODUCTION}

How is UK's university admission? This is a crucial question which has been discussed for a long time nowadays. Is it fair and efficient to allocate students to schools using the current method? Is there any other ways to allocate them more efficiently and increase equality? Can we make it better by changing the allocation mechanism system?

In England, there is a record that 27.9 percent of the 18-year-old students have been accepted through UCAS. In Wales, 26.3 percent of young people will start an undergraduate course, which is also a record. In Northern Ireland, the entry rate is 28.1 percent. Scottish students received their exam results last week, and 25.9 percent of all 18-year-old students have now been accepted. In total, more than 353,960 people from across the UK have been accepted so far this year. There is 2 percent decrease compared to A level results day 2017. A total of 411,860 students have been placed on an undergraduate course so far. There is 1 percent decrease on A level results day last year, despite a $2.5 \%$ drop in the number of 18-year-old students in the UK population. Among those accepted, $88 \%$ will study their first choice course [1]. It can see that the percentage for young people to go to universities successfully is quite low. It is really vital to increase it as the country's innovation and better-off depends on education and young people very much.

Hiba K. Massoud \& Rami M. Ayoubi’s study shows that the understanding of the factors affecting student enrollment by firstly providing a review of previous literature on internal and external motivators of student choice in HE (Higher Education), and secondly by examining one important under-investigated system factor, FAS (Flexible Admission Systems), in relation to actual demand measured by enrollment and student number growth[2]. The literature review showed that most prior studies focused on students' choices and/or satisfaction and were mainly based on questionnaires. It indicated that family, social class, friends and personal inspiration are key internal motivators and that distance, image of the host country, institutional reputation, general institutional factors, general academic factors such as the mode of study, and the academic system are key external motivators for student choice in HE. However, it reveals that scholars in the field of HE have 
paid little attention to the relationship between university admission systems and student enrollment.

Thus, can we actually manage to increase the percentage of students going to universities by improving the current allocation system? That is the question that the author wants to figure out.

\section{CURRENT STATE}

So how is the current UK's university allocation system and how does it work to connect students and universities side?

Currently, most students who study A-level in colleges in the UK are using UCAS (The Universities and Colleges Admissions Service) system to apply to universities. Students can choose to apply five universities with the equal preference ranking, and they need to provide their A-Level subjects and predicted grades, one personal statement and references. Then they will wait for schools to make decisions which school gives them conditional offer or rejection. Conditional offer is an offer which contains some requirements where students can go to the school if they can meet these requirements later. Normally these requirements are about final A-level grades and English Language Requirement. After receiving all replies from the five schools that they choose, they will make a firm and insurance choice and turn down all others school choices. After taking the final A-Level exam, students will hand in their grades in UCAS. If their grades satisfy those conditions, they will get their unconditional offers from schools that they have chosen. The system will match them with their firm choice school first, comparing to the insurance choice school. If they cannot meet, they will be rejected and then go to Clearing system where they will have to use current grades to see if any other universities are satisfied with them and are willing to take students on Clearing system.

The matching mechanism used now is highly independent from one school to another, which means the schools act as actors in the market instead of just resources. So the schools can have their own preferences over students and each of them has different priorities ranking. Students, from another side, are also actors in the admission market. However, schools have no strict priority ranking or no specific preference. For example, when schools consider to accept a student, they do not only depend on predicted grade, personal statement or reference, and sometimes they combine these things together to make decisions. Students can also have their own preferences but they have no specific preference ranking over the five universities that they choose to apply. There is no sequential order when they choose their five choices. As a result, schools have no strict priorities and students have no strict preference rankings.
Professor Aytek Erdil's study shows that although universities effectively generate such rankings as a by-product of their admissions process, there is no mechanism within the current system which integrates all information across the system to help coordinate offers in an effective way. Instead, in a completely decentralised fashion, universities make offers without knowing what offers their applicants might be holding. Thus the universities' task of deciding whom to make offers while controlling their student in take numbers is a complicated strategic problem. It is strategic in the sense that the outcome of the process (who will study where, how many students will be in each course, etc.) depends on the complex interaction of offer decisions made by all universities, choices made by all students including those with multiple offers, and so on. In particular, in order to control their intake numbers, the universities need to make offer decisions on the basis of not only predicting A-level grades of their applicants, but also predicting all other decisions made by all other actors in the system [3].

As a result, is the UK's current university admission system really reliable and equal for students and universities? There might be some existing problems in the matching mechanism. So how can we address or change that for the best of both sides?

\section{EXISTING PROBLEMS}

Is it a good way to allocate students and schools? What are the possible existing problems that might worse off students and universities? And most importantly, how can we redesign the mechanism to be more efficient and beneficial for both side's perspective and achieve a better matching. Is there any other better allocation mechanism, such as deferred acceptance or immediate acceptance mechanism, which we can use and put them into UK's university allocation system?

\subsection{Instability}

This matching mechanism system is not stable for both students and schools, so stability cannot be achieved in this model. There can exist individual block. For example, in every year, there are students who are rejected by every universities they applied to or cannot go to schools that they have firmly chosen after receiving their grades, which means the universities find them unacceptable. And if a student fails to go to all his five school choices, even if he gets some offers from the Clearing system, he may not be satisfied with those schools and then not accept them. In this case, he will try to apply to his outside choices such as schools in other countries. Pairwise blocking also exists in this kind of matching system. For example, when student A gets conditional-offer from school A using his predicted grades to apply and student B is rejected from it. After 
the final A-level exam, B actually succeeds to get higher grades than student $\mathrm{A}$. In this case, school $\mathrm{A}$ wants student $\mathrm{B}$ more than student $\mathrm{A}$, and student $\mathrm{B}$ wants to go to school A more than his current choice. As a result, the union of student $\mathrm{B}$ and school $\mathrm{A}$ is wanted for both of them, which means they will be happier to have each other than any other options. Both individual and pairwise blocking exist, so the matching is not stable. This is a bad thing because this indicates the system is out of balance.

\subsection{Pareto-efficiency}

Pareto-efficiency is when an economy has its resources and goods allocated to the maximum level of efficiency, and no change can be made without making someone worse off [4]. In such case, even if we do not take student A into account, student B can still be rejected in first step if his predicted grade is not ideal. In this case, there is a welfare loss between student B and school A. Without making anyone else worse off, student B and school A could have been better off to match with each other based on student B's excellent final A-level grades. Thus the system is Pareto-inefficient which allocates students and universities inefficiently and results in welfare loss in both sides.

\subsection{Strategy-proof}

Strategy-proof is where the best response for any player to act in a game is to tell the truth and it weakly dominates all other actions. Strategy-proof cannot be achieved as well because students can lie about their true preferences. For example, a student who wants to ensure his university place will select one or two choices which is listed in his preference ranking order after his 5 th choice. So he can have more chance to get in those universities compare to his actual 4th or 5th choice. So the five choices do not always reveal his real preference, or it is not strict. In this such matching mechanism, students will always struggle to think about their strategies when applying through UCAS within only five choices. And there is definitely no guarantee that they will tell their true preferences. This will result in market failure which means the market cannot allocate resources optimally.

\section{DEFERRED ACCEPTANCE (DA)}

By introducing Deferred Acceptance (DA) mechanism into UK's university admission system, some issues might be solved. The Gale Shapley algorithm (also known as the deferred acceptance algorithm or propose-and-reject algorithm) is an algorithm for finding a solution to the stable matching problem.
We assume that students have strict preference towards schools and ranked by orders. Schools also have more strict priorities towards students. And students will only apply to the schools which they are achievable in every conditions schools give. Both students and schools have enough ranking option choices. Then we can run the algorithm by the following steps.

Step 1: Every student apply to their first choice university and each school tentatively holds their preferred and acceptable students and rejects all other students.

Step 2: Student rejected in Step1 apply to their next highest choice university. And each school considers both new applicants and the students held at Step1 tentatively, considers preferred acceptable students from this combined set of students, and rejects the rest.

Repeat the steps as above. The algorithm continues until when no more applicants are made.

We assume there are three students and three universities in the market: Student 1, Student 2 and Student 3; University 1, University 2 and University 3. The preferences ranking is listed below. An example is Student 1 prefer University B the most, and then University A, the last preferred choice is University C.

Table 1: Student 1, 2, 3's preferences ranking of University A, B, C.

\begin{tabular}{|l|l|l|}
\hline 1 & 2 & 3 \\
\hline B & C & B \\
\hline A & B & C \\
\hline C & A & A \\
\hline
\end{tabular}

Table 2: University A, B, C's preferences ranking of Student 1, 2, 3.

\begin{tabular}{|l|l|l|}
\hline A & B & C \\
\hline 1 & 2 & 3 \\
\hline 2 & 1 & 1 \\
\hline 3 & 3 & 2 \\
\hline
\end{tabular}

Run the DA algorithm steps above and we can find the student-optimal stable matching (SOSM):

Table 3: Student 1, 2, 3 and University A, B, C matching outcome

\begin{tabular}{|l|l|l|}
\hline 1 & 2 & 3 \\
\hline A & B & C \\
\hline
\end{tabular}

Which means the outcome under the DA algorithm mechanism is that Student 1 matches with University A; Student 2 matches with University B; Student 3 matches with University C. 


\subsection{Stability}

In this case, both students and schools will not find each other unacceptable and they will not choose their outside choice so it is individual rationally and no school nor student will find the matching unacceptable. There is no coalition blocking for any size, which shows its group stability. It is always going to be the student-optimal stable matching (SOSM) outcome. A stable matching exists and can be found via a "deferred acceptance" algorithm [5]. This does not violate student's priority for schools, not waste school's capacity and helps controlling the number of students they accept.

\subsection{Strategy-proof}

And it is always strategy proof for proposer which is students. Because students will not need to lie or cut their preference ranking, doing so will not give them any advantage at all. So what the system collects reveal all students' true demands. In this way, strategy-proof can be achieved. This makes it safe for students to be truthful and removes the burden to strategies. Also strategy-proofness makes it safer for the policy maker to rely on the revealed preferences to carry out welfare analysis.

Thus, under Deferred Acceptance mechanism, strategy-proofness can always be achieved.

\subsection{Pareto-efficiency}

Pareto-efficiency may not exist under the Deferred Acceptance Algorithm Matching. The example above shows that under DA algorithm, the stable matching is (SOSM):

Table 4: Student 1, 2, 3 and University A, B, C matching outcome

\begin{tabular}{|l|l|l|}
\hline 1 & 2 & 3 \\
\hline A & B & C \\
\hline
\end{tabular}

However, if we change the matching outcome slightly, such that Student 2 matches with University C instead of University B and Student 3 matches with University B instead of University C:

Table 5: Student 1, 2, 3 and University A, B, C matching outcome 2

\begin{tabular}{|l|l|l|}
\hline 1 & 2 & 3 \\
\hline A & C & B \\
\hline
\end{tabular}

This result dominates the SOSM result because Student 2 and Student 3 are both better-off and Student 1 stays the same. Student 2 prefers University $C$ more than University B and Student 3 prefers University B more than University C. As a result, there is someone who are better-off without making anyone else worse-off in the market. Which is a Pareto-improvement. So we might not gain Pareto-efficiency using DA algorithm.

\subsection{Some problems under Deferred Acceptance}

However, whether Deferred Acceptance mechanism can give a better matching for UK's university admission system actually depends on many other factors and variables.

It is hard to control the number of the students every year and the capacity of schools. If the number of students increase beyond schools' capacity, we assume there is going to be a shortage as the demand exceeds the maximum supply. There will be many students failing to go to schools, which is considered a market failure. Or the school capacity changes can make a difference as well.

Pareto-efficiency might not be achieved under such mechanism, which is always going to be a big shortcoming under Deferred Acceptance as resources cannot be allocated optimally.

Also, is it possible for students to give all their preference rankings in respect to every universities in the UK? The number might be massive and hard to control.

And is the DA mechanism really feasible and achievable in the UK? Many universities might have the abilities to accept students outside UCAS or the matching system. They can give students unconditional offers and ask them to promise to accept. In such case, students might not want to go through the process as they have received the satisfied offers from the schools.

\section{POSSIBLE POLICIES FOR SOLUTION}

Instead of using predicted grades, government can introduce a centralized exam at the end of AS year and use that grade. In this case, it is more fair as different schools have different ways to predict students' grades. Just $16 \%$ of students actually match the marks they were predicted [6]. It shows that the percentage which the actual grade matching with predicted grade successfully is significantly low. So the predicted grade method is inefficient. It is also hard to control and give a standard to each high schools when predicting grades. The predicted grades giving by each school are unequal, sometimes unjustified and highly depend on different high schools or teachers. Another way which can make students better-off is applying to universities only after receiving their final A-LEVEL exam grades, in this way, they will not suggest to guess what grades they might have and the universities can have more clearer sight on every applied students. Moving to a post-qualification admissions (PQA) system where people apply to 
university after they get their results would deal with the problem of inaccurate grade predictions, abolish the chaotic clearing system, make unconditional offers redundant and level the playing field for students [7].

\section{CONCLUSION}

In conclusion, there are many existing problems created in UK university admission system, so how to solve those issues and increase efficiency to make both students and universities better is a big discussion nowadays in the UK. This paper points out some possible problems in the current system such as instability, Pareto-inefficiency and unfair allocation. Then puts the Deferred Acceptance mechanism into the matching process in the admission system in the UK. If the DA algorithm can be run properly, stability and strategy-proof can be achieved. This means that comparing to the current system, Deferred Acceptance matching makes students and universities better-off. Also, a more stable environment existed is beneficial for both students and universities to focus more on academic fields. The more efficient matching in the university admission system can lead them to achieve the better goals. However, whether the Deferred Acceptance mechanism gives both students and universities a better matching depends on many other factors like the number of students in total and a open and transparent system. It requires more researches statistics and detailed real life examples to show and prove its benefits and advantages. As a result, although the Deferred Acceptance mechanism might give a better matching result than the current system, more researches need to be conducted to show a clearer instruction for the UK's university admission system.

\section{REFERENCES}

[1] UCAS website

DOI: https://www.ucas.com/corporate/news-and-key-doc uments/news/record-percentage-young-people-areuniversity

[2] Hiba K. Massoud \& Rami M. Ayoubi. (2018). Do flexible admission systems affect student enrollment? Evidence from UK universities, Journal of Marketing for Higher Education, pp. 11. DOI: $10.1080 / 08841241.2018 .1562507$.

[3] Battal Dogan. University of Bristol. Aytek Erdil, University of Cambridge. (2021). A Modern Design for University Admissions in the UK. pp. 13.

[4] Investopedia. (2020). Pareto Efficiency. By the Investopedia team. Fact checked by Michael Logan. Review by Thomas Brock. DOI: https://www.investopedia.com/terms/p/pareto-effic iency.asp
[5] D. Gale and L. S. Shapley. (1962). College Admissions and the Stability of Marriage. The American Mathematical Monthly, 69(1), pp. 9-15.

[6] Dr Gill Wyness. (2016). Predicted grades: accuracy and impact. A report for University and College Union. UCL Institute of Education. pp. 2.

[7] Jo Grady. (2019). University admissions fail students. Let's give places for real grades, not predictions. The Guardian. 